\title{
st \\ Selección de grupo y altruismo: el origen del debate
}

Patricia Mareghal

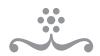

RESUMEN

Uno de los problemas más discutidos en la biología evolutiva es la identificación de los niveles sobre los que opera la selección natural. Usualmente se acepta que Darwin sostenía que la selección natural actúa a nivel del individuo. Sin embargo, otra línea de interpretación sugiere que Darwin concibió que la selección natural podía actuar a nivel de grupo, específicamente, que se vió obligado a sostener esto para explicar el comportamiento altruista. Este trabajo pretende mostrar que Darwin no esbozó un modelo claro de selección de grupo y que recurre a explicaciones de selección a nivel del individuo para dar cuenta del comportamiento altruísta. Defiendo esta lectura apelando a pasajes de su obra que considero que introducen la influencia del parentesco y la selección individual como fuerzas que explican el comportamiento altruista y que son la perspectiva desarrollada por los modelos actuales de aptitud inclusiva y altruismo recíproco.

PaLABras-clave • Teoría de la evolución. Selección natural. Adaptación. Niveles de selección.

Selección de grupo. Altruismo.

\section{INTRODUGGIÓN}

Uno de los problemas más discutidos en la biología evolutiva es la identificación de los niveles sobre los que opera la selección natural. Usualmente se postula que Darwin sostiene que la selección natural actúa a nivel del individuo (cf. Mayr, 1991). Sin embargo, según algunos autores, algunos pasajes de su obra parecen sugerir que concibió que la selección natural podría actuar a nivel de grupo (cf. Wilson, 2002). Wilson e Sober (1994) sostienen que Darwin pareciera recurrir a este nivel de explicación a la hora de dar cuenta del comportamiento altruista tanto en la especie humana como en otras especies, al ser incapaz de poder dar cuenta del surgimiento de este tipo de conductas mediante la actuación del mecanismo evolutivo a nivel individual.

Sin embargo, considero que Darwin no esbozó un modelo claro de selección de grupo y sólo sugiere su posibilidad en algunos pasajes reducidos de su obra, apelando a explicaciones a nivel del individuo a la hora de presentar y desarrollar su teoría. 
El hecho de que no haya suscripto explícitamente a niveles supra-individuales de selección determinó una serie de debates, en el escenario post-darwinista, acerca de cómo debemos interpretar su explicación de los comportamientos cooperativos y altruistas de las especies sociales y, al mismo tiempo, dió inicio a una serie de trabajos y discusiones acerca de los niveles en los que opera la selección natural, modelos que siguen siendo motivo de discusión en la actualidad.

Este trabajo pretende remontarse al origen del debate acerca de si la selección natural puede actuar a nivel de grupo, recurriendo al análisis de ciertos pasajes de la obra de Darwin. En particular, me remitiré a aquellos pasajes que nos sugieran (o nos disuadan de) que, efectivamente, Darwin tenía en mente este tipo de explicación. Así, en la sección 1, me ocuparé del vínculo entre la evolución por selección natural a nivel de grupo y la explicación del comportamiento altruista en las especies. En la sección 2, examinaré los pasajes donde Darwin exploró el comportamiento altruista, los cuales suelen ser citados a favor de la idea de que sostuvo la selección de grupo, al tiempo que analizaré cuál de los modelos contemporáneos se acerca más a la posición que Darwin delineó en su obra. En la sección 3, examinaré las ambigüedades en el concepto de adaptación que pueden rastrearse en la obra de Darwin y que tienen impacto en el debate acerca de la posibilidad de que la selección natural actúe a nivel de grupo. Finalmente, presento las conclusiones.

\section{Selegción natural y altruísmo}

Mantener que la selección opera a nivel de grupo es sostener que el proceso de la selección natural actúa sobre la diferencia de aptitudes que exhiben dos o más grupos. La selección de grupo propone que hay una competencia por la supervivencia entre grupos de organismos y no entre organismos individuales. Lo que es adaptativo a un nivel, puede no serlo en otro nivel. Por lo tanto, la selección de grupo permite resolver casos en los que un rasgo a explicar parece maladaptativo a nivel del individuo pero le confiere mayor éxito reproductivo al grupo del que éste forma parte.

Darwin nunca abordó explícitamente el problema de a qué nivel opera la selección natural y sólo parece recurrir a la selección de grupo en unos pocos pasajes de su obra que discutiremos en este trabajo. Al igual que en muchos de los debates actuales acerca de la teoría de la evolución, podemos rastrear el origen de la discusión acerca de los niveles de selección en la obra de Darwin y en las aparentes contradicciones o vaguedades en las que parece incurrir. 
La tesis fundamental de Darwin (1859) es que el cambio evolutivo se debe al surgimiento de variaciones heredables en el seno de una población y a la supervivencia diferencial que se traduce en un mayor éxito reproductivo de ciertos individuos (que exhiben algunas de estas variaciones) por sobre otros. Es el éxito de un individuo en términos de que posee ciertos rasgos lo que le permiten enfrentarse de manera más adecuada a los desafíos que le impone su ambiente. El mecanismo de la selección natural requiere de un requisito que Darwin denomina (metafóricamente) lucha por la existencia, de clara inspiración en la obra del economista británico Thomas Malthus (1798). En la naturaleza, hay recursos limitados (especialmente los recursos alimenticios) y esto determina una lucha por esos recursos entre los organismos. Este supuesto consiste en la idea de que nacen más individuos que aquellos que pueden sobrevivir, dada la limitación de recursos disponibles. Esto determina consecuencias en la capacidad de los organismos para dejar descendencia. Aquellos organismos que pueden acceder a los recursos sobrevivirán en mayor proporción y, por lo tanto, exhibirán una reproducción diferencial dejando mayor descendencia en comparación con aquellos organismos que no resultaron exitosos en la lucha por el alimento. De este modo, toda la explicación de la selección natural que ofrece Darwin parece ubicarse a nivel del individuo.

Sin embargo, hay ciertas características que exhiben algunas especies que, intuitivamente, parecen contradecir esta explicación. Específicamente, los comportamientos altruistas parecen difíciles de acomodar mediante un modelo de selección individual (cf. Rosenberg, 1992). El comportamiento altruista se suele definir como acciones que resultan en un incremento de la tasa reproductiva o en la supervivencia de uno o más individuos, al mismo tiempo que causa una disminución en la supervivencia o reproducción del sujeto que realiza la acción. Un comportamiento altruista puede variar en el grado de beneficio que le provee al receptor, así como en el grado de sacrificio que requiere del actor. El altruismo ha sido observado en una serie de especies que van desde los virus e insectos sociales hasta los primates.

El altruismo es difícil de explicar a partir de los modelos básicos de selección natural, que predicen que un individuo exhibirá rasgos y comportamientos que buscan satisfacer el interés propio, tendientes a incrementar su propia aptitud, es decir, su supervivencia o éxito reproductivo. Es por esta dificultad, que presenta la teoría darwinista para dar cuenta del comportamiento cooperativo, que el problema del altruismo en la obra de Darwin merece y recibe especial atención. Así, hay autores que sostienen que en los textos de Darwin hay evidencia de que este autor considera que la selección es un proceso que ocurre en una variedad de niveles. En lo que sigue, me ocuparé de analizar esto. 


\section{DARWIN Y LA SELEGGión DE GRUPO}

En esta sección, examinaré los pasajes donde Darwin exploró el comportamiento altruista, los cuales suelen ser citados a favor de la idea de que sostuvo la selección de grupo. Al mismo tiempo, analizaré cuál de los modelos contemporáneos se acerca más a la posición que Darwin delineó en su obra.

El concepto de selección natural que fue desarrollado por Darwin en El origen de las especies (1859) está descrito en términos de selección entre individuos. Darwin sostuvo que de la lucha por la existencia que se sucede por la tendencia de las poblaciones a crecer más que las reservas de alimento disponibles, se sigue un cambio gradual en las especies o evolución. El mecanismo que provee para explicar este cambio evolutivo es la supervivencia diferencial y la mayor tasa reproductiva de aquellos individuos que poseen rasgos favorables frente a aquellos que no los poseen. Estos rasgos favorables seleccionados suponen una mayor adaptación del organismo a su ambiente. La inspiración malthusiana de Darwin le permite arribar a su teoría de la selección natural a partir de la lucha por la existencia. Esta lucha es explicada como una competencia dentro de las especies, es decir, entre los miembros de una población. La lucha intra-específica es lo que le permite postular que ese proceso conduce a cambios en la misma especie, es decir, a una evolución de la especie en cuestión.

La competencia por la obtención de los recursos limitados entre iguales (una competencia severa, dado que las necesidades de estos individuos, por ser semejantes, son las mismas) le permitió a Darwin concebir la selección natural como una fuerza creativa capaz de generar el cambio evolutivo y no meramente como una manera de mantener a las especies separadas y homogeneizar y diferenciar a las mismas. Es este modelo lo que explica el énfasis puesto en sus explicaciones en que la selección natural opera a nivel del individuo, y que ha conducido a las interpretaciones ulteriores acerca de que las poblaciones están compuestas por individuos "egoístas". La selección individual se refiere a la selección de aquellos rasgos que contribuyen a la supervivencia y reproducción diferencial del actor relativa a sus congéneres.

Desde esta teoría resulta claro que es difícil dar cuenta del comportamiento altruista. Darwin fue consciente de que ciertos rasgos y comportamientos suponían un problema para su propuesta. Evidencias acerca de que tenía presente esta dificultad la encontramos en pasajes como:

Indudablemente podrían oponerse a la teoría de la selección natural muchos instintos de explicación muy difícil: casos en los cuales no podemos comprender cómo se pudo haber originado un instinto (Darwin, 1859, p. 235). 
Como muchos investigadores posteriores, Darwin fue consciente, específicamente, del problema que el comportamiento altruista suponía para su teoría:

Es extremadamente dudoso que los descendientes de padres más bondadosos y benévolos, o de aquellos que eran los más fieles a sus camaradas, hayan sido engendrados en mayor número que los descendientes de padres egoístas y traicioneros pertenecientes a la misma tribu. El individuo que prefiere sacrificar su vida antes que hacer traición a los suyos, a menudo no dejará descendencia que herede su naturaleza noble. Apenas parece posible, por lo tanto (admitiendo que sólo nos ocupemos de una tribu victoriosa sobre otra), que el número de hombres dotados de estas virtudes, o el grado de perfección, hayan podido aumentar por selección natural, o sea por sobrevivir el más apto (Darwin, 1871, p. 163).

El hecho de que Darwin notara que este tipo de rasgos es difícil de conciliar con la teoría de la selección natural, tal como la presenta, parece indicar que su modelo básico era el de una fuerza o proceso que actúa a nivel del individuo, que surge a causa de la lucha por la existencia entre individuos de una misma especie y que determina que las adaptaciones deban exhibirse a nivel del individuo para la supervivencia y beneficio de éste. Ante el problema que le presentan los rasgos mencionados, y para ser consecuente con su idea de que cualquier comportamiento puede ser explicado mediante la apelación a la teoría de la selección natural, es posible que haya introducido otros niveles de actuación del mecanismo. Sin embargo, considero que Darwin nunca ofreció un modelo explícito del funcionamiento de la selección natural para niveles supra-individuales.

En un pasaje de El origen de las especies, frecuentemente citado para apoyar la idea de que Darwin concibió la selección de grupo (cf. Wilson, 1992, 2002; Wilson \& Sober, 1994), el autor trata de superar el reto que supone para su teoría la existencia de miembros estériles en ciertas colonias de insectos. La presencia de castas estériles es un caso extremo de sacrificio de la capacidad reproductiva para aumentar la aptitud del grupo. Darwin sostiene:

[A]lgunos insectos y otros animales articulados, en estado natural, resultan accidentalmente estériles; y si estos insectos hubiesen sido sociables, y si hubiese sido útil para la sociedad el que cada año hubiese nacido un cierto número, capaces de trabajar pero incapaces de procrear, yo no sé ver dificultad alguna especial en que esto se hubiese efectuado por selección natural (Darwin, 1859, p. 236). 
Sin embargo, a pesar de que este pasaje parece sugerir la selección de grupo, Darwin no apela explícitamente a la misma. De hecho, en pasajes ulteriores, la explicación que provee de este fenómeno parece indicar que su origen es el resultado de una estrategia reproductiva óptima del individuo, que supone la producción de una mezcla de descendencia fértil y estéril que ayuda a la supervivencia y reproducción de los fértiles:

Podemos llegar a la conclusión de que pequeñas modificaciones de estructura o de instinto relacionadas con la condición estéril de ciertos miembros de la comunidad han resultado ser ventajosas y, en consecuencia, los machos y hembras fecundos han prosperado y transmitido a su descendencia fecunda una tendencia a producir miembros estériles con las mismas modificaciones. Este proceso tiene que repetirse muchas veces, hasta que se produzca la prodigiosa diferencia que vemos entre las hembras fecundas de la misma especie en muchos insectos sociables (Darwin, 1859, p. 238).

El beneficio del grupo parece ser sólo un subproducto de una aptitud específica que beneficia al individuo. Este último pasaje parece indicar que no es necesario apelar a la selección a nivel de grupo para explicar la existencia de las castas estériles y, por lo tanto, que Darwin no se aparta de la explicación individual con la que introdujo la selección entre individuos de una misma especie. Un acto que parece altruista es en realidad el resultado de las estrategias del individuo para maximizar su propio éxito reproductivo. Esta explicación solucionaría el problema aparente que se le presentaba a la teoría de la selección natural postulando que, mediante una observación más cuidadosa, se descubre que los comportamientos que le parecen altruistas al etólogo, en realidad le proveen beneficios al actor altruista.

Otro pasaje citado (Wilson \& Sober, 1994), como evidencia de que Darwin apoyaba a la selección de grupo, es en el cual se plantea su explicación del origen y desarrollo de las cualidades intelectuales y morales en el ser humano en El origen del hombre:

No debe olvidarse que aunque un grado muy elevado de moralidad da a cada individuo y a sus hijos pocas o ninguna ventaja sobre los demás hombres de la misma tribu, un incremento en el número de hombres bien dotados y un avance en nivel moral ciertamente otorgará una ventaja inmensa de una tribu sobre otra [...] resultaría victoriosa sobre la mayoría del resto de las tribus, y esto sería selección natural (Darwin, 1871, p. 166). 
A pesar de lo desarrollado en este pasaje, considero que el mismo no nos aporta evidencia contundente a favor de que Darwin haya concebido que la selección natural actúa a nivel de grupo. Pretenderé esbozar una lectura alternativa de la propuesta de Darwin en la cual se postula que la selección natural actúa sólo a nivel del individuo a la luz de propuestas contemporáneas sobre la conducta altruísta.

\subsection{LOS PRIMEROS MODELOS DE SELEGGIÓN DE GRUPO \\ Y LA aptitud inclusiva o selección de parentesco}

Desde un punto de vista histórico, el primero en plantear un modelo sistemático de selección de grupos fue Sewall Wright (1986 [1932]), uno de los fundadores de la genética de poblaciones y responsable de la síntesis entre la teoría de la evolución darwinista y la genética clásica mendeliana. Se trata de un modelo de selección entre grupos que, a diferencia de lo esbozado por Darwin y de los modelos ulteriores, no fue desarrollado para explicar el altruismo. La línea que plantea la naturaleza jerárquica de la selección natural se cristaliza en la obra del zoólogo británico Wyne-Edwards, quien afirma que la selección de grupos es aún más importante que la selección a nivel del individuo. En su libro de 1962, que trata de la relación entre la distribución de los animales y el comportamiento animal, plantea que las poblaciones regulan su tamaño en un nivel menor a las posibilidades que permitiría el ambiente en el que se desarrollan y que, cuando la población se acerca al nivel que le impone su ambiente, los miembros disminuyen su tasa reproductiva. Lo que postula este autor es que los individuos se auto-restringen por motivos altruistas y disminuyen su tasa reproductiva en detrimento de su propia supervivencia favoreciendo la supervivencia del grupo al cual pertenecen. Este comportamiento altruista sólo puede explicarse postulando la selección a nivel de grupo y no del individuo. La obra de Wyne-Edwards (1962) introduce de manera explícita, por primera vez, la relación entre la evolución del altruismo y la selección de grupos.

Frente a este modelo, podemos rastrear en la literatura una serie de intentos por explicar el origen evolutivo de este comportamiento a partir de las relaciones de parentesco que siguen una propuesta desarrollada por el genetista y biólogo británico John Haldane (1932), otro de los protagonistas de la nueva sintesis junto con Sewall Wright y Fisher. Haldane sostiene que las acciones altruistas hacia parientes próximos favorecen la supervivencia y proliferación de los genes que el altruista comparte con esos parientes. Si la aptitud se mide en términos de la supervivencia de los genes del individuo, el proceso por el cual se favorece la supervivencia de los parientes cercanos a expensas de la propia supervivencia o reproducción, en realidad, enmascara un aumento de la aptitud dado que incrementa la supervivencia de ciertos genes. 
Quien desarrolla esta idea hasta convertirla en un modelo es el biólogo británico William Hamilton (1964) sosteniendo que los actos altruistas se realizan para favorecer a los parientes próximos en tanto portadores de los mismos genes que el ejecutor de la acción. Hamilton introduce el concepto de aptitud inclusiva o selección de parentesco, que supone que se seleccionarán aquellas estrategias que dejen el mayor número de copias de un gen (o grupo de genes) que las codifica. En el caso de organismos de reproducción sexual, usualmente, aunque no necesariamente, serán los hijos. Una estrategia que sacrifica a un hijo para salvar a dos o más sobrinos, padres o hermanos asegurará tantas o más copias del gen que si beneficiara a la progenie. El concepto de aptitud inclusiva supone una combinación entre la aptitud del organismo con la aptitud de sus parientes (con quienes comparte copias de los mismos genes). El altruismo surge como una estrategia adaptativa para un individuo que es parte de un grupo de parientes. Luego, para explicar el altruismo no es necesario postular la selección a nivel de grupos puesto que será seleccionado a nivel de individuo (en tanto vehículo de los genes), porque supone una adaptación, es decir, la estrategia óptima para la reproducción y supervivencia de los genes que porta ese individuo. Así, cuando un individuo ayuda a un pariente sólo está ayudando a la parte de sí mismo representada en los genes del pariente. Esta es una forma de altruismo "aparente" que enmascara una forma de "egoísmo".

Si consideramos otro de los pasajes que Darwin le dedica a la explicación del comportamiento altruista en el origen de las facultades morales, parece que su idea es más cercana a la propuesta de Hamilton, quien puede haber desarrollado su propuesta a partir de una lectura de la obra de Darwin. Darwin relaciona la aptitud reproductiva, que supone el comportamiento altruista, con la "simpatía", identificando que la causa inmediata del comportamiento caritativo es este sentimiento. Entre individuos en los que surge este sentimiento de simpatía, Darwin identifica un factor que puede favorecer la selección de estas emociones y las acciones que surgen a partir de las mismas. Este factor es el parentesco:

Es evidente, en primer lugar, que los impulsos instintivos tienen distinto grado de fuerza en la humanidad, un salvaje pondría en riesgo su propia vida para salvar a un miembro de la misma comunidad, pero sería totalmente indiferente ante un extraño. Una madre joven y tímida impulsada por el instinto maternal correría el mayor de los peligros por su propio hijo, sin dudarlo un momento, pero no por cualquier otra criatura (Darwin, 1871, p. 87).

Este pasaje abona la propuesta de que Darwin tenía en mente un tipo de selección individual para explicar el comportamiento altruísta. El parentesco sería la fuerza 
que da cuenta de los comportamientos cooperativos, en tanto los individuos emparentados son portadores de variaciones heredables. Por lo tanto, la supervivencia de las variaciones adaptativas portadas por un individuo y sus parientes sería la fuerza que opera detrás de los comportamientos altruistas.

\subsection{Altruísmo sin parentesco: el modelo del altruísmo recíproco}

Otra forma para dar cuenta del altruismo fue propuesta por el biólogo y sociólogo americano Robert Trivers (1971) a través de la noción de reciprocidad. Su teoría, denominada altruismo recíproco, puede dar cuenta de casos de comportamiento altruista entre individuos no emparentados, hecho que la teoría de la selección de parentesco no podía explicar. Esta idea supone que un individuo realizará un sacrificio con la expectativa de obtener un beneficio que aumentará su propia supervivencia y capacidad reproductiva a largo plazo. Esta explicación fue influenciada por la teoría de juegos y dio lugar a modelos matemáticos de cómo se favorece la transmisión de estos rasgos. (No entraré en detalle en este tipo de modelos porque exceden el propósito de este trabajo y su desarrollo requiere la introducción de la teoría de juegos. Mi interés es señalar que brinda una explicación del altruismo mediante un proceso de selección individual.) Frente a una oportunidad de cooperar, la mejor estrategia para el individuo es hacerlo ante la expectativa de una devolución del "favor" a largo plazo. La reciprocidad se convierte en altruismo cuando la obtención de beneficios a largo plazo es ignorada por el actor. Todo acto de sacrificio, tarde o temprano, puede ser recompensado, por lo tanto, supone una adaptación para el individuo exhibir este rasgo y la selección del mismo ocurre a nivel individual.

Las acciones altruistas respecto de individuos no emparentados son consideradas por Darwin como casos parasitarios del mismo instinto de preservación y cooperación que se observa con los parientes. El instinto seleccionado para beneficiar a los familiares puede conducir a casos de altruismo exogámicos por una automatización o aplicación refleja de la conducta seleccionada para resguardar a los individuos consanguíneos.

Tales acciones [...] parecen ser el simple resultado de la mayor fuerza de los instintos sociales o maternales más que de cualquier otro instinto o motivo; dado que estos se ejecutan demasiado instantáneamente para que haya tiempo de reflexionar (Darwin, 1871, p. 87).

Los pasajes transcriptos parecen sugerir que lo que Darwin tenía en mente al hablar del origen de los comportamientos altruistas no era la selección a nivel de gru- 
po. A pesar de requerir una explicación más sofisticada y a pesar de que la teoría de la selección individual, a primera vista, no parece aplicarse en este caso, la especulación que proporciona Darwin busca conciliar el origen de estas capacidades con la teoría de la selección natural propuesta para el origen de las especies. Dado que Darwin no ofrece un modelo claro de la selección de grupo, quizás podemos intuir que no descartaba que el origen de estos instintos ocurriera por la selección actuando a nivel del individuo, resultando en una aptitud diferencial para él y para el grupo social del que forma parte. Si esto es así, Darwin no está postulando la selección de grupo para dar cuenta de este problema, sino un caso especial de selección individual. La naturaleza selecciona una estrategia que permite la supervivencia del mayor número de individuos que comportan los mismos rasgos del actor altruista (partiendo de la heredabilidad de los rasgos seleccionados).

\section{AdAPtAGión y NIVELES DE SELEGGión}

Claramente, Darwin admite que la presencia de estos instintos altruistas beneficia a un grupo y mejora sus posibilidades de sobrevivir. Pero si Darwin no tenía en mente la idea de que la selección natural opera a nivel del grupo, ¿por qué menciona "ventajas" de una tribu sobre otra tal como lo hace en el pasaje citado anteriormente? Esta pregunta se relaciona con lo que Elisabeth Lloyd (1992) denomina "la pregunta acerca del beneficiario", la cual plantea quién se beneficia por el proceso de selección natural: ¿La presencia de adaptaciones en un nivel significa que la selección natural opera en ese nivel?

Algunos autores han considerado necesario distinguir entre niveles sobre los que opera la selección natural y niveles donde se manifiesta el producto de la selección natural (cf. Lewontin, 1970; Dawkins, 1976; Hull, 1980; Brandon, 1982; Walton 1991). Es decir, distinguir entre la unidad de selección y la unidad que se beneficia por la selección. Esta distinción es crucial a la hora de discutir la necesidad de invocar la selección de grupo para explicar ciertos rasgos. Así, un defensor de la selección de grupo insistirá en esta correlación entre "nivel adaptado" y "nivel de selección". Por ejemplo, Wilson (1992) sostiene que explicar las adaptaciones de un grupo requiere que invoquemos un proceso de selección natural en el nivel apropiado, es decir, selección de grupos.

En el debate acerca de la existencia de selección de grupo parece siempre partirse de la idea de que el nivel donde opera la selección es el nivel que exhibe adaptaciones. Esto supone cierta confusión derivada de qué es a lo que llamamos adaptación, una noción poco clara que en Darwin parece oscilar entre dos sentidos diferentes: 
1 Adaptación como cualquier rasgo que es el resultado de un proceso de selección natural en ese nivel. Cualquier rasgo que surge de un proceso de selección es, entonces, por definición una adaptación.

2 Adaptación como rasgos que son "buenos" para sus poseedores, en el sentido de hacerlos más aptos en relación a su ambiente.

Si lo que Darwin tenía en mente al hablar de "ventajas" de un grupo respecto de otro era la primera acepción de adaptación, entonces estaba postulando la selección de grupo, dado que sólo mediante ésta podía explicar un rasgo que supone una adaptación a ese nivel. Si, en cambio, lo que Darwin tenía en mente, al hablar de "ventajas" para los grupos en virtud de la presencia de rasgos altruistas, es una aptitud del segundo tipo, podría argumentarse que el grupo resulta beneficiado por un proceso de selección que no opera necesariamente a ese nivel, sino a nivel del individuo. De hecho, puede argumentarse que, en última instancia, el proceso de selección de cualquier rasgo que encuentra su explicación mediante selección individual conduce a largo plazo a una mayor aptitud de la especie, en el sentido de estar mejor adaptada a su ambiente natural. La especie o población total puede ser la beneficiaria de la selección individual al mismo tiempo que los individuos seleccionados son beneficiados. Las adaptaciones pueden presentarse simultáneamente en varios niveles, sin embargo, esto no implica que la selección opere en todos esos niveles.

\section{Conclusión}

El texto de Darwin contiene la génesis de los debates ulteriores acerca de los niveles de selección y esboza algunos de los principios de los distintos modelos que se ofrecen en la actualidad para explicar el comportamiento altruista. En su obra encontramos elementos que parecen indicar que el comportamiento altruista suponía un reto para la selección a nivel individual que había propuesto. Indudablemente, la idea de que la selección puede actuar a nivel de grupo encuentra algunos pasajes de apoyo en la obra de Darwin. Intenté mostrar en este trabajo que esos pasajes no son conclusivos y que, a la luz de otros fragmentos, puede pensarse que no era esto lo que Darwin tenía en mente. Para esto, señalé aquellos pasajes que considero que introducen la influencia del parentesco y la selección individual como fuerzas que explican el comportamiento altruista y que son la línea explotada por los modelos actuales de aptitud inclusiva y altruismo recíproco.

Para resumir los puntos centrales de mi trabajo, pretendí en el mismo señalar y argumentar que: 
1 Los debates acerca de la selección de grupo, en el plano de la teoría evolutiva, se vinculan con la necesidad de explicar el comportamiento altruista, estando ya esta relación esbozada en la obra de Darwin.

2 Algunos de los modelos alternativos para explicar el comportamiento altruista que están en discusión hoy en día, a saber, la selección inclusiva y el altruismo recíproco, fueron sugeridos y encuentran su génesis en distintos pasajes de la obra de Darwin.

3 Darwin sostiene que la selección natural opera a nivel del individuo de manera consistente a lo largo de su obra, es decir, propone un tipo de explicación del altruismo y del comportamiento cooperativo en las especies, el cual postula la selección a nivel del individuo y no a nivel de grupo.

4. El uso ambiguo que Darwin hace de la noción de adaptación ha tenido consecuencias en los debates acerca de los niveles en los que opera la selección natural, principalmente, sobre la posibilidad de que este mecanismo actúe a nivel de grupos. Sin embargo, una noción de adaptación como rasgo útil y beneficioso, permitiría explicar el comportamiento altruísta manteniendo que la selección natural sólo opera a nivel del individuo, aunque el beneficiario de la adaptación sea el grupo al cual éste pertenece.

Patricia MareghaL Profesora del Departamento de Filosofía, Universidad de Buenos Aires. Miembro de proyectos de investigación, Consejo Nacional de Investigaciones Científicas y Tecnológicas, Conicet, Argentina. patricia.marechal@gmail.com

\begin{abstract}
One of the most debated issues in evolutionary biology concerns the level at which natural selection operates. It is usually accepted that Darwin maintained that natural selection operates at the individual level. However, another line of interpretation suggests that Darwin conceived that natural selection could operate at the group level as well, specifically, that he was forced to accept this in order to explain the altruistic behavior. This paper aims to show that Darwin did not provide a clear model of group selection, and that he had recourse to explanations of selection at the individual level in order to explain altruistic behavior. I will defend this interpretation through passages in his texts that introduce the influence of parenthood and individual selection as forces that explain altruistic behavior and that appeal to the same points exploited by the contemporary models of inclusive fitness and reciprocal altruism.
\end{abstract}

KEYwords • Theory of evolution. Natural selection. Adaptation. Levels of selection.

Group selection. Altruism. 


\section{REFERENGIAS BIBLIOGRÁFIGAS}

Brandon, R. The levels of selection. PSA: Proceedings of the Biennial Meeting of the Philosophy of Science Association, 1, p. 315-23, 1982.

DARwin, C. On the origin of species by means of natural selection. London: Murray, 1859. The descent of man. London: Murray, 1871.

Dawkins, R. The selfish gene. New York: Oxford University Press, 1976.

Haldane, J. The causes of evolution. London: Princenton University Press, 1932.

Hamilton, W. D. The genetical evolution of social behavior. Journal of Theoretical Biology, 7, p. 17-52, 1964 . Hull, D. Individuality and selection. Annual Review of Ecology and Systematics, 11, p.311-32, 1980.

Keller, E. F. \& Lloyd, E. (Ed.). Keywords in evolutionary biology. Cambridge: Harvard University Press, 1992.

Lewontin, R. The units of selection. Annual Review of Ecology and Systematics, 1, p. 1-18, 1970.

Lloyd, E. Unit of selection. In: Keller, E. F. \& Lloyd, E. (Ed.). Keywords in evolutionary biology. Cambridge: Harvard University Press, 1992. p. 334, 4 .0.

MaLthus, T. Essay on the principle of population as it affects the future, Dutton, NYC, 1798.

MaYr, E. One long argument. Cambridge: Harvard University Press, 1991.

Provine, W. B. (Ed.). Evolution: selected papers. Chicago: Chicago University Press, 1986.

Rosenberg, A. Altruism: theoretical contexts. In: Keller, E. F. \& Lloyd, E. (Ed.). Keywords in evolutionary biology. Cambridge: Harvard University Press, 1992. p. 20-8.

Trivers, R. The evolution of reciprocal altruism. Quarterly Review of Biology, 4.6, p.35-7, 1971.

WaLton, D. The units of selection and the bases of selection. Philosophy of Science, 58, 3, p. 417-35, 1991.

Wilson, D. S. Group selection. In: Keller, E. F. \& Lloyd, E. (Ed.). Keywords in evolutionary biology. Cambridge: Harvard University Press, 1992.

Darwin's cathedral: evolution, religion and the nature of society. Chicago: The University of Chicago Press, 2002.

Wilson, D. S. \& Sober, E. Reintroducing group selection to the human behavioral sciences. Behavioral and Brain Sciences, 17, 4, p. 585-654, 1994 .

Wright, S. The roles of mutation, inbreeding, crossbreeding and selection in evolution. In: Provine, W. B. (Ed.). Evolution: selected papers. Chicago: Chicago University Press, 1986 [1932]. p. 356-66.

Wynne-EDwards, V. G. Animal dispersion in relation to social behavior. London: Oliver \& Boyd, 1962.

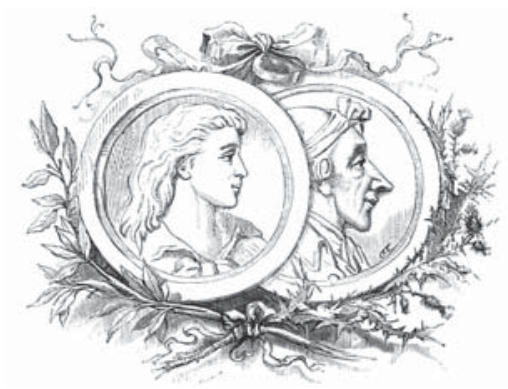

